\title{
O prazer como um bem no De Voluptate de Lorenzo Valla
}

\author{
Pleasure as the good in Lorenzo Valla's De Voluptate
}

\section{Ana Letícia Adami"}

Resumo: O pensamento estoico que refloresceu no Renascimento teve na figura de Valla um perturbador antagonista. Aluno de reconhecidos apreciadores da escola, como o chanceler florentino Leonardo Bruni, Valla foi responsável por apresentar uma ideia não apenas original na crítica ao estoicismo, como para a refutação humanista ao ensino escolástico. A querela se refaz pela dramatização do confronto entre um estoico e um epicurista a respeito das causas do verdadeiro e do falso bem (summum bonum). A obra onde o humanista concebe o debate é o diálogo De Voluptate (Do Prazer, I43I). Embora se constitua como seu primeiro trabalho de fôlego, nele ele lança as premissas que o acompanharão nas obras posteriores, fazendo de sua obra um legado uno e orgânico. A questão primordial que aí nos apresenta é a da disjuntiva entre o bem e o prazer. O que acontece quando um ato deixa de ser bom? Pela tradição estoica, ele não pode coincidir com o bem, mesmo que satisfaça uma de nossas inclinações, como a fome e a sede, pois o bem só pode ser contemplado onde pouse a virtude. O problema abordado por Valla, porém, sugere outra questão: o que acontece quando o ato deixa de ser prazeroso? Tentarei mostrar brevemente alguns aspectos que permeiam o problema conforme tratado por Valla no De Voluptate.

Palavras-chave: epicurismo; estoicismo; prazer

Abstract: The stoic philosophy that flourished in Italy during the Renaissance encountered in Lorenzo Valla a troublesome antagonist. A former pupil of some of the most renowned

\footnotetext{
"Universidade de São Paulo, doutoranda em Filosofia (bolsista CAPES).

I Hazlitt, Willian. "On classical education" (I998, p. 9).
} 
connoisseurs in stoicism at the time, such as the Florentine chancellor Leonardo Bruni, Valla was responsible to introduce not only an original and critical view of stoicism, but also a humanist refutation of scholastic education. The querulous tone is reanimated by a dramatization of an opposition between a stoic and an epicurist regarding the origins of the true and false good (summum bonum). The work where the humanist thinker best conceived and exposed this controversy is De Voluptate (On Pleasure, I43I), written in dialogue form. Although this is one of Valla's first major works it was the one that set the premises for his later works, which gives them a unifying and organic legacy. The central question that presents itself to us is that of a disjunctive relation between good and pleasure. What happens when a moral act is no longer good? According to stoicism, it cannot coincides with good, even though it indulges one of ours inclinations, as hunger or thirsty, since good can only be contemplated where virtue rests. However, the question addressed by Valla suggests another issue, namely, what happens when a moral act is no longer pleasurable? In this paper, I will endeavor to show briefly some aspects that permeate it as dwelt by Valla in his De Voluptate.

Keywords: Epicureanism; Stoicism; pleasure

\section{Introdução}

O pensamento estoico que floresceu no período do Renascimento no século XV teve na figura de Lorenzo Valla um perturbador antagonista ${ }^{2}$. Desde Petrarca, e com mais força nos discursos de Leonardo Bruni, ou mesmo de Coluccio Salutati, que o antecedeu na chancelaria, podemos notar o quanto o estoicismo contribui para moldar o tom e o conteúdo de seus discursos. Sempre preocupado com a forma que um escrito deve adotar, Valla põe-se a tecer uma crítica a esse modelo, aproveitando-se da filosofia que, segundo a tradição, diametralmente lhe é oposta: o epicurismo. Por meio da notícia da descoberta do texto de Lucrécio, De Rerum Natura, em 1917, por Poggio Bracciolini, Valla elabora sua defesa epicurista do prazer como um bem por oposição à concepção estoica de bem. Esse é o tema que ele desenvolve na sua obra De voluptate, de I43I.

O texto, escrito originalmente em latim, conheceu sua primeira edição crítica em I970, graças ao trabalho da filóloga ítalo-americana Maristella de Panizza Lorch, seguido de

\footnotetext{
${ }^{2}$ Para mais sobre a presença do pensamento estoico no Renascimento, ver a obra de Paul Oskar Kristeller e Léontine Zanta nas referências bibliográficas.
} 
uma tradução em língua inglesa de 1977 pela mesma autora. Por tratar-se de uma obra escassamente conhecida no Brasil - mesmo a nível internacional podemos dizer que seu reconhecimento é recente, se considerarmos que a data da primeira tradução em língua francesa é de 2004, publicada sob os apelos efusivos de Michel Onfray ${ }^{3}$-, vale a pena incluirmos aqui uma apresentação em linhas gerais da obra, chamando a atenção para questões que não apenas estão no núcleo do tema abordado pelo humanista, mas que também interessaram a autores mais familiares a nós, como Gérard Lebrun, a fim de aproximar a obra cada vez mais do público atual.

Lebrun, no muito importante artigo A Neutralização do Prazer, nos faz refletir a questão sobre se os termos hedoné e voluptas "evocavam ao espírito dos antigos apenas as ideias de gula, bebedeira e luxúria" (Lebrun, 2006, p. 45I), como em geral se pensaria nos dias de hoje. E chama nossa atenção para os vários estudos eruditos, como exemplarmente o de Michel Foucault, no Uso dos Prazeres, que nos mostram o "quanto devemos desconfiar de leituras anacrônicas", ainda mais quando se trata desse "domínio" - entenda-se, do prazer -, que são "mais ou menos constantes" (Lebrun, 2006, p. 45I).

Em relação a Valla e ao De Voluptate não é diferente. Muita maledicência foi-lhe conferida desde sua primeira publicação em I43I. Por força do Tribunal da Santa Inquisição, a obra foi incluída em 1559 no Index de Livros Proibidos ${ }^{4}$ e sua circulação e reprodução vetadas. Ainda por conta desta obra, o humanista fora obrigado a responder a um processo inquisitorial em I443, do qual somente saíra a salvo graças à intervenção do rei Afonso de Aragão, a quem era de grande estima.

Nos dias atuais, contudo, podemos entender seu obscurecimento, em parte, como extensão do problema levantado por Lebrun a respeito do emprego irrefletido que fazemos da palavra "hedonismo", que não considera o "que faz a especificidade da sabedoria do século IV a.C. em relação à questão do prazer" (Lebrun, 2006, p. 452); de outra parte, a rótulos que a própria historiografia conferira ao autor. Entre esses, o primeiro e mais conhecido que podemos destacar é o de "o pai da história moderna"; isto é, o exemplo cabal do filólogo que empenha a espada de sua arte a fins bem práticos: contestar formalmente a pretensão jurídica da doação de Constantino à Igreja ${ }^{5}$. Segundo: o de ter sido o primeiro a revestir com uma forma original o conteúdo do dogma do livre-arbítrio e

\footnotetext{
${ }^{3}$ Michel Onfray, filósofo francês, é uma das principais figuras da atualidade no campo de estudos sobre o epicurismo. Em seu Prefácio à primeira tradução do De voluptate em língua francesa, exclama: "Plus de cinq siècles après sa première parution en Italie en I43I le De voluptate dispose enfin d'une traduction en langue française... Un demi millénaire de silence! Cinq cent ans d'ignorance! Faut-il en rire ou pleurer?”, p. iii.

${ }^{4}$ Ver mais a respeito na obra de Eugênio Garin.

${ }^{5}$ Para um tratamento crítico a esse respeito, recomendo a excelente reflexão de Francisco Murari Pires.
} 
da providência divina sem, no entanto, os colocar em perigo. E por último, o responsável pela tentativa frustrada de renovar o modelo filosófico hedonista numa espécie de “epicurismo-cristão"6.

Não pretendo com isso meramente supor que não sejam corretos, ou mesmo julgar o quanto da "essência" do autor eles podem verdadeiramente exprimir, mas apontar para o cuidado que se deve ter em relação a eles: do quanto podem ser redutores e, na pior das hipóteses, acabar não por despertar a curiosidade intelectual, mas por suprimi-la, dando como finita a recensão crítica de suas obras. Os dois primeiros rótulos que apresentei foram extraídos do brilhante livro de Cassirer, Indivíduo e cosmos na Filosofia do Renascimento, mas os mesmos podem também ser encontrados, uns mais, outros menos, em inúmeros outros autores que se ocuparam do tema. O que estou sugerindo é que a leitura de textos como esse, em geral nosso ponto de partida, ou de entrada, no universo da cultura renascentista italiana, não pode se subtrair à tarefa de leitura dos textos originais dos humanistas.

\section{O De Voluptate}

O texto, construído na forma de diálogo, é dividido em três livros mais um Proemio. Neste, Valla expõe claramente sua principal intenção: discernir sobre a "causa do verdadeiro e do falso bem": "Fui arrebatado pelo desejo de lidar, o quanto for humanamente possível, com as verdadeiras virtudes, através das quais nós atingimos o verdadeiro bem" (Adami, 20I0, p.58).

O problema, embora não mencionado diretamente pelo autor, encontrava-se já entre os grandes pensadores do século IV a.C., como Platão e Aristóteles. Assim nos diz Lebrun: "Quanto a esse ponto, Platão, Epicuro e Aristóteles estão perfeitamente de acordo. O prazer é bom por si mesmo, o prazer é um bem e, se deixa de sê-lo, é somente quando a dor a ele se junta" (Lebrun, 2006, p. 452).

Tratava-se do tema da distinção dos prazeres, que Platão enumerava no Filebo, que podem figurar junto ao bem supremo, a eudaimonía- na versão valliana, o paraíso, descrito na última das três partes da obra (livro III): "Neste livro não será irrelevante compor uma espécie de elegia do paraíso o mais esplêndida possível, a fim de evocar, o quanto eu for capaz, os ânimos dos ouvintes à esperança do bem verdadeiro" (Adami, 20Io, p. 6o-6I).

\footnotetext{
${ }^{6}$ A ordem de exposição dos rótulos que segue não se ateve à ordem cronológica de publicação das obras do autor às quais se referem, mas a uma ordem que acredito refletir, aproximadamente, o grau decrescente de extensão e reconhecimento desses rótulos.
} 
A tessitura desse terceiro e último livro não se conduz, assim, pelo fio da confrontação de argumentos de um lado e outro do debate (disputatio in utramque partem), tal qual se seguira desde a escola de retores da Nova Academia até os cursos de Artes Liberais do século XV. Mas se trata, como assinalado pelo próprio autor, de uma copiosa descrição do paraíso, em que a empunhadura da palavra pela retórica - pois que Valla associava à Eloquência a figura de uma Rainha com uma espada na mão - cede lugar ao pincel, para alçar o leitor à magnitude figurativa de um céu cujas palavras nos remetem a imagens de forte apelo sensual: “Todos aqueles vastos campos, de sorriso agraciado por todas as cores e fragrâncias divinas, e todo aquele agradável ar, serão repletos de anjos de várias nuances e matizes" (Adami, 20I0, p.263).

Bem diferente desta elocução e estilo, no entanto, é a que encontramos nos dois primeiros livros, em que o peso dos argumentos aprofundam o caráter filosófico-dialógico do texto. De modo geral, a obra fica assim dividida, segundo o próprio autor: "O primeiro livro mostra que o prazer é o único bem; o segundo, que a honestidade dos filósofos nem ao menos é um bem; e o terceiro, trata do verdadeiro e do falso bem" (Adami, 20Io, p. 6o).

Ainda no Proêmio ao primeiro livro, deparamos com a exposição pontual do problema para o qual todo o debate da obra converge: o tratamento das "verdadeiras virtudes através das quais atingimos o verdadeiro bem" (summum bonum). Ele organiza o diálogo seguindo a trilha de um movimento, como ele mesmo afirma, de baixo para o alto, ou seja, lidando primeiro com os bens "desta vida" para só então passar aos da "vida futura" no terceiro livro (Adami, 20Io, p. 58). A maior parte da obra, portanto, é dirigida ao tratamento daquelas virtudes por meio das quais podemos tornar nossa vida terrena mais feliz, e assim, garantir uma vaga naquela felicíssima no céu. Com esse intuito, concorrem o pensamento de duas escolas filosóficas diametralmente opostas: a dos estoicos e a dos epicuristas, que diferem-se justamente na distinção daquelas virtudes comprometidas como bem supremo. É neste ponto que o autor precipita uma tese polêmica, pois que contradiz a resposta estoica creditada pela tradição ecumênica e largamente aceita entre os estudiosos humanistas:

(...) visto que os estoicos afirmaram mais do que todos os outros o valor da honestidade, isto me parece suficiente para elegê-los como nossos adversários e assumir a defesa dos epicuristas. O porquê disso explicarei mais tarde. Somados, estes três livros tem por objetivo refutar e destruir a raça dos estoicos (Adami, 20Io, p.6o). 
A polêmica, no entanto, não está apenas no ataque à nação estoica, que ocupava lugar de grande prestígio entre os estudiosos das humanidades; nem mesmo na asserção, um tanto provocadora (aliás, bem do agrado do autor), de que a defesa da honestidade, como proposta pelos estoicos, fosse motivo de repreensão. Mas fundamentalmente pela filiação convicta ao partido epicurista na designação sobre o verdadeiro bem. Nas palavras do interlocutor epicurista no diálogo: "O que deve ser chamado de bem [bona], entretanto, é assunto de grande controvérsia entre nós dois" (Adami, 20IO, P.89) - o que revela a consciência de Valla da forte oposição que o aguardava, outrossim, tomando o cuidado de não contradizer sua fé cristã, sempre incólume.

\section{O Diálogo}

A narrativa principia situando-nos em meio a um círculo de eruditos, incluso o próprio autor, que figuravam entre os principais centros humanísticos de seu tempo, como os de Florença, Pavia e Roma ${ }^{7}$, e que personificavam, cada um, uma área de interesse dos studia humanitatis. Para falar de alguns, encontramos entre eles homens da nobreza ilustrada, como Antonio Bossio, aluno de Valla; homens devotados à Igreja e ao estudo da teologia, como o vigário Antonio Bernerio e o monge franciscano Antonio Raudense, também professor de retórica; o médico Giovanni Marco; e aqueles que se dedicavam quase que exclusivamente às artes oratórias, como os juristas Catão Saco e Guarino Veronese, e o poeta Maffeo Vegio. Valla seleciona dois dentre esses para disputar uma controvérsia acerca da vida humana e dos meios de se alcançar a felicidade. Como era de se esperar, ele convida um estoico e um epicurista para a tarefa ${ }^{8}$.

\section{O Estoico}

A disputa é iniciada com os lamentos daquele que apelidarei aqui de o "príncipe" estoico da narrativa, o jurista Catão Saco - faço uso da palavra "príncipe" aqui não em sentido denotativo, isto é, no sentido da função civil de um príncipe, mas em sentido figurado, referindo-me àquele que mais e melhor condensou em si as características

\footnotetext{
${ }^{7}$ Difícil é determinar e estabelecer esses círculos com precisão em vista da movimentação contínua dos humanistas entre os lugares.

${ }^{8}$ Refiro-me aqui à segunda versão da obra, seguindo a escolha da editora crítica. Há duas versões distintas modificadas pelo autor que variam não no conteúdo, mas no estilo, na escolha das personagens e local. Por exemplo: os debatedores principais Maffeo Vegio e Catão Sacco vêm a substituir Antonio Panormita e Leonardo Bruni, respectivamente. Ver mais em Introdução à obra de Maristella De Panizza Lorch.
} 
estoicas, do mesmo modo como fez David Hume naquele genial ensaio $O$ estoico, e de modo semelhante, como pretendeu Valla. Os lamentos desse "príncipe dos estoicos" devem-se à constatação de quão grande é a impiedade com que a Natureza nos castiga, infligindo-nos uma enormidade de vícios, maior em número do que o exército das virtudes, de modo que nos sintamos tal qual soldados atacados simultaneamente pelos dois flancos, e desprovidos de defesas. Sem contar a impiedade própria à natureza humana, amante, na maioria das vezes, desses mesmos vícios. Como ser feliz diante de espetáculo terreno tão miserável? Assim lamenta-se Catão:

Ó Natureza a quem chamamos e acreditamos ser nossa mãe, agrada-te ter nos provido com uma defesa tão pequena diante de um exército tão forte e, em batalha tão difícil, ter-nos dado um espírito tão fraco que prefere ser vencido a vencer; e ainda, não sendo nós completamente vitoriosos, nos persegue e nos pune com uma vingança imediata e terrível? (Adami, 20I0, p.76).

$\mathrm{Na}$ assistência desse dilema o estoico não se omite: não ousa permanecer no repouso do ócio. E desse modo, Catão propõe aos amigos, que se encontravam em um momento de lazer sob o Pórtico de São Gregório em Roma, discutir um assunto da maior utilidade: acerca da honestidade e do bem:

$\mathrm{E}$ dos muitos tópicos que me vieram à mente, eis aqui o assunto mais oportuno, segundo penso: frequentemente me pergunto com grande perplexidade acerca da perversidade e fraqueza da alma comuns à maioria dos homens (...) Os homens, como eu os vejo, são fortemente inclinados a adquirirem coisas que não são boas por natureza, ou que certamente não são comparáveis em nenhum ponto de vista à virtude" (Adami, 20Io, p.66).

O estoico, investido de quanta abundância e solenidade o estudo da retórica podem lhe conferir, emprega toda sua arte e indústria para resolução, ou, talvez, consolação, das maiores aflições humanas. Sem desmerecer o conhecimento e o exemplo dos antigos gregos e latinos - e sem abdicar jamais de sua fé, embrenha-se, em nome da razão, sua porção mais divina, na especulação filosófica. Desde fins da Antiguidade, houve muitos filósofos cristãos que contribuíram para consolidar o longo matrimônio do estoicismo coma teologia cristã. Lembremos, por exemplo, de Boécio, o influente teólogo romano de quem Valla nutria manifestas discordâncias. Assim ele diz pela boca de Maffeo Vegio: 
Quase que por imitação a esses e quase como um estoico, Boécio, seguindo, como acredito, Górgias de Platão, discutiu tal assunto amplamente na sua obra A Consolação da Filosofia, e mostrou no seu quarto livro, que o bem verdadeiro, que nunca falta aos bons, mas sempre aos maus, era quase igual à honestidade (Adami, 2010, p.232).

A personificação do estoico de Valla no diálogo é um tipo de temperamento austero, cujo orgulho, revestido de falsa modéstia, é desvelado pelo emprego de um estilo áspero e empolado, só tolerado graças à honestidade reconhecida do orador. Estilo retórico que, aliás, Valla aprendeu a imitar, em parte, graças ao ensino da escolástica tradicional, de outra parte, graças aos estudos humanísticos, lecionados pelo chanceler de Florença, Leonardo Bruni, de quem Valla tomou lições. O famoso magistrado italiano, admirador de Cícero, apreciava profundamente a escola filosófica com a qual o orador romano tinha grande afinidade: o estoicismo. É certo, como afirma Kristeller, e salientamos de início, o estoicismo, familiar desde a Idade Média através dos textos de Cícero e Sêneca, ocupou no século XV um lugar crescente, coroado posteriormente com as publicações de Justus Lipsius e Guillaume Du Vair, na segunda metade do século XVI.

Pode-se atribuir seu sucesso ao fato de que o estoico, ao depositar toda sua confiança na razão humana - benefício que não apenas distingue o homem dos animais, mas que também lhe permite afastar-se de toda bestialidade para criação de leis e conveniências que só o emprego da arte e da indústria podem ofertar-, impele estes homens, em nome de faculdade tão nobre, ao cultivo da razão e ao exercício da vontade. Considera que o homem, com uma mãe natureza mais severa do que em relação a qualquer um dos outros animais, nada adquiri sem labor e diligência. Ele ambiciona, pelo uso e pela prática, lapidar seus defeitos - os da mente e do corpo. Acredita que o grande fim de toda indústria humana é alcançar a felicidade e, por isso, cabe-lhe conceder a cada arte particular o seu justo valor em quinhão. E depois, então, de ter estudado e fixado com cautela toda a ordem das condutas e ocupações, poderá dizer ter encontrado aí a verdadeira felicidade e favorecido, ainda que um mínimo, à beatitude daquela multidão que se chama a turba. Assim ele diz:

Eu não disse essas coisas para lamentar as vicissitudes do vosso destino, ou até mesmo do meu, pois que nós, com muito trabalho e vigília, maiores do que a racionalidade humana parece ser capaz, conseguimos nadar até a 
superfície. No entanto, eu me compadeço da condição daqueles não dotados de diligência, e que, por assim dizer, não sabem nadar. E vós sabeis o quão grande é a multidão daqueles que, não injustamente, nós chamamos por aquele nome familiar, a turba ignorante (Adami, 20ı, p. $71)$.

Aqueles que se destacam acima de toda arte subalterna atuam como o artesãomestre que, pondo juntas todas essas partes, as governa harmonicamente tal qual conduz as engrenagens de uma máquina. Para essa função concorrem duas figuras: a do filósofo, que vê no cultivo da razão pelo ensino da escolástica o melhor caminho para alcançar o grande templo da sabedoria; e a do orador público, herdeiro dos passos de Cícero, crítico da indiferença dos filósofos, que não descura das afecções sociais. A honestidade e as virtudes (essa separação entre virtus e honestas é de Valla) são seus materiais: a justiça, a prudência, a magnanimidade, a fortaleza, a temperança e a constância ${ }^{9}$. Reforçando os ideais da vida ativa em detrimento da especulativa, o estoicismo é como uma túnica púrpura que veste bem ao magistrado que faz do seu dever civil uma arte, para mover paixões e convencer multidões.

Ora, Valla jamais quis ser este homem. Embora tenha servido na corte real - a de Afonso I de Nápoles -, como muitos humanistas, jamais foi este o seu desejo e fim, mas o de guarir a Cúria Pontifícia; posto que, lamentavelmente, para ele, só a muito custo, e no fim da vida, chegou a ocupar. Sua busca de reforma é mais profunda: no sentido de descer às raízes que engendram o próprio ato do pensar. Não visa diretamente uma pragmática política; embora tenha clareza do poder de alcance de suas ideias. Uma delas, e talvez a principal, que permeia em alguma medida todas as suas obras, está contida aqui, no De voluptate: a tese do prazer como um bem.

\section{A retórica valliana}

O epicurismo, então renegado pela teologia cristã como a escola dos mal intencionados, dos desonestos, dos "libertinos" e dos preguiçosos, reaparece no debate de Valla como autêntico argumento crítico, e não vexatório. Ao invés disso, é Catão, nosso "príncipe" estoico, que será motivo do deboche. É com gargalhadas que o poeta Maffeo Vegio, nosso "príncipe" epicurista, depois de ouvir falar o estoico, se dirige aos doutos

\footnotetext{
${ }^{9}$ Cf. Valla em referência a Cícero, De officis.
} 
reunidos. Suas risadas expressam, além do desprezo pelas ideias do antagonista, o temperamento de um debatedor vivaz e licencioso, que emprega um discurso igualmente licencioso e mais frouxo (menos solene e mais coloquial):

Embora eu veja que Catão está comovido não apenas em seu discurso, mas também em sua alma, eu não posso evitar, todavia, o riso, ao pensar que um orador tão grande, sob cujo patronato uma causa jamais foi ameaçada, possa desviar tanto do ponto e falar contra seu próprio intento. Para prevenir-me de que alguma censura diga que minha risada é maldosa, antes mesmo de começar a falar, afirmo que o que me agradou não foi a traição dele contra si mesmo, e sim porque favorecera o meu lado (Adami, 20IO, p. 77).

$\mathrm{Na}$ retórica de Valla existe um artifício bem claro: o discurso deve se conformar à honra e à dignidade do conteúdo. Afinal, diz ele: "o que é menos apropriado do que expressar assuntos sublimes apressadamente e grandes assuntos com humildade?" (Adami, 20Io, p. 204). Essa proposta tem também outra razão, que ele deixa ainda mais evidente: todo o saber, que se expressa e se produz por meio da linguagem, tem por Rainha, a Eloquência. "A Filosofia - diz ele - não passa de um soldado ou tribuno sob suas ordens" (Adami, 20IO, p. 8I).

Essa rainha, governante de todas as artes, abarca três tipos de discursos: dois com o fim de ensinar e comover - tipo que se adequa ao dos dois debatedores do diálogo, o estoico e o epicurista - e um terceiro cujo fim é o deleite - caso empregado pelo juiz final do diálogo, o franciscano Antonio Raudense (Adami, 20IO, p. 197). Essa divisão do discurso segundo dois fins - a utilidade da instrução persuasiva e o prazer (o mesmo que deleite) foi por Valla extraída da Arte Poética de Horácio do mesmo excerto onde o poeta nos diz: “Tem todos os votos quem misturou o útil ao agradável, deleitando e, ao mesmo tempo, instruindo o leitor" (Horácio, I993, v.340). Valla encontrou nele um aliado preciso. O prazer e a utilidade, sem dever nada àquilo que é honesto, quando postos juntos, se harmonizam numa composição perfeita. "Pois todas as coisas - diz o humanista - dependem do prazer e não do que é honesto[honestatem]" (Adami, 20ı, p. 89).

Como excelente retórico, Valla recorre às fontes exatas de onde tomar emprestado seus argumentos. E quando o empréstimo não é evidente, ou ele outorga a si certas adequações, se adianta e corretamente nos diz: "Ora, é lícito pegar argumentos para a nossa própria tese de qualquer lugar que nos agrade!" (Adami, 20Io, p. 8I). Com isso, quero 
chamar a atenção para o quanto Valla mantém sempre no seu horizonte a coerência. Nada lhe escapa: a escolha do cenário; das personagens, cujos nomes são associados a tal e tal fama e ocupação; a forma e estilo empregados em cada fala; a ordenação das ideias e argumentos internos de cada discurso particular e deles entre si no todo da narrativa; enfim, tudo isso faz de sua obra de uma arquitetura impressionante. Submete-se, de boa vontade, às exigências que a aprendizagem da Eloquência pode proporcionar, convencido de se tratar de algo bom, isto é, um bem. O belo é bom e, como nos agrada, gera prazer e, por isso, é dito um bem, como defende ele em sua obra.

\section{O prazer como bem}

O "bem" é definido como "aquele que é desejável por si mesmo e não em razão de nenhum outro bem" (Adami, 20I0, p. 92) ou fim - afirmação que Valla, sem o menor pudor, toma de empréstimo do próprio Sêneca, do partido estoico ${ }^{\mathrm{IO}}$. Como já dito antes, segundo o humanista, não há o menor problema em pegar um argumento do partido oposto, uma vez que compreende ser a tarefa do orador buscar a verdade e jamais a defesa cega de um ou outro lado. Esse ponto é de fato um argumento forte para a concepção que o autor faz do papel do orador e da retórica. E por isso, me parece relevante o cuidado de não incorrermos facilmente, a nosso gosto, na atribuição de classificações e etiquetas ao autor, como se ele tivesse feito de Epicuro o seu mestre. Como dissemos antes, para ele só a Eloquência é a rainha de todas as coisas.

O prazer visto dessa maneira, como um bem, ou o verdadeiro bem, é a tese epicurista rechaçada pelos estoicos e recuperada por Valla. Para fins de ilustração, tomo emprestado uma citação de Lebrun em que simula um estoico atordoado perante a designação de seus adversários: "Como é que se pode, com a maior naturalidade do mundo, conciliar prazer e virtudes morais sob a mesma rubrica de 'Bem'?”(Lebrun, 2006, p. 470). O problema, segundo os estoicos, não estaria em coibir os prazeres sensíveis, que eles chamam de inclinações (como fugir da fome, do frio, da sede, os quais nos levam a ter boa saúde), mas em identificar nessas coisas o bem supremo, encontrado, segundo sua acepção, somente naquilo que é o honesto. É absurdo, dessa maneira, considerar que o prazer, como a honestidade, seja um bem em si. Valla, seguindo os passos de Epicuro, afirma absolutamente o inverso: "a palavra honestidade em si é superficial, trivial e inteiramente prejudicial (...); nada além do prazer deve ser perseguido” (Adami, 20ı, p. 93).

\footnotetext{
${ }^{10}$ A afirmação também se encontra em Platão, A República.
} 
"Esse axioma”, afirma Lebrun, para nós modernos, “já não vale mais" (Lebrun, 2006, p. 453). O estoicismo venceu a batalha. E sua vitória é atribuída graças a uma confusão linguística: "de uma sensação de prazer que experimento, dizemos que ela é agradável, não boa" (Lebrun, 2006, p. 453). Parece que Valla, o excelente gramático, percebeu muito antes de Kant, essa confusão e tentou corrigi-la - mas sem distinguir entre juízos éticos e de gosto. Primeiro, tratou de repor o que já havia sido dado, ou seja, tomar o prazer como um substantivo, como substância. Neste caso, dizer que o "prazer é um bem", do ponto de vista gramatical, é o mesmo que dizer: "Jesus é amor". Isso equivale a dizer que "Jesus é algo". Esse "algo" corresponde ao "amor". Assim, voltando à oração anterior, devo entender que "o prazer é algo"; esse "algo" corresponde ao "bem" - Valla diria, ainda, "ao verdadeiro bem". Por outras palavras, não se está falando de uma qualidade, mas da substância do ser. A mesma posição coincide em Epicuro, mas também em Aristóteles e Platão, como bem nos elucida o texto de Lebrun.

Já para a honestidade, Valla reserva o lugar de adjetivo, sintagma que qualifica o ser. Portanto, a respeito de algo e de sua honestidade, apenas posso dizer se ele é honesto ou desonesto. "A honestidade" em si - diz Valla - "não é nada" (Adami, 20Io, p. 200). Daí, sobre o prazer, sendo ele um substantivo, isto é, dotado de substância, é possível dizer se ele é honesto ou desonesto. E só ele pode ser dito um bem, não a honestidade. Os prazeres, na visão do debatedor epicurista de Valla, o poeta Maffeo Vegio, são bens ou presentes concedidos pela Natureza aos homens. Cabe a esses saberem utilizar-se honestamente daqueles.

Para concluir, é preciso acrescentar que o prazer [voluptas] dito "um bem" só vale para o verdadeiro. Será falso, ou vergonhoso - como seria dito pelos "estoicos mais rabugentos" - ou, ainda, "estúpido" (Lebrun, 2006, p. 47I), quando a ele se misturar alguma dor. Se o prazer é o bem em si, a dor é o mal. Aqueles que procuram conforto para um estado de dor extrema no corpo ou na alma não erram em dizer serem tais gozos prazeres, mas podem errar ao colocá-los entre os verdadeiros bens. Para os estoicos, a questão que permeia a definição do prazer como um bem em si, afirma Lebrun, está em distinguir “o agradável aparente do agradável falso" (Lebrun, 2006, p. 455). A triagem de prazeres que Platão opera no Filebo tem o intuito de decidir quais prazeres podem figurar junto ao bem supremo (a eudaimonía) e distinguir os verdadeiros dos falsos. Não exatamente assim procederá Valla, apesar de coincidir na preocupação. Para ele, todos os prazeres podem figurar no paraíso, pois que são eles todos presentes de Deus aos homens. 


\section{Conclusão}

No terceiro e último livro do De voluptate, pela voz de Antonio Raudense, o autor tece uma espécie de elegia do paraíso celeste, rica em referências aos prazeres que o corpo pode desfrutar conforme cada um de nossos sentidos. De Platão a Valla, devemos notar a presença de um componente crucial: a fé cristã. Se só aos bons, os honestos, é concedido entrar no Reino de Deus, lá saberão experimentar da mesma forma que gozaram em vida dos mesmos, e ainda maiores e melhores, prazeres antes encontrados na vida terrena. Um homem bom não se regozija na dor alheia; daí que ao sádico jamais será concedido atravessar as portas do céu. Platão não viu isso; nem poderia, pois que não conhecia a misericórdia de Cristo. Nesse ponto da discussão, Valla, em mais uma demonstração de aguda consciência de suas escolhas, apela aos verdadeiros mestres da doutrina cristã, os Pais da Igreja, para que fique bem claro que é unicamente à fé cristã, e a nenhum filósofo, que ele recorre.

O fechamento do diálogo, pois, fica a cargo do homem que, por consenso, sustenta a adequada dignidade, o temor às coisas divinas e o engenho reconhecido no uso dos recursos oratórios para emitir um discurso que deleite aos ouvidos e instrua a alma. Este homem é o monge franciscano Antonio Raudense. É importante lembrar que é sempre a mesma mão, a de Valla, que escreve, e mesmo se Raudense chegue a decidir a favor dos epicuristas, está se referindo à lição precisa do debate: se é ou não o prazer um bem, ou a honestidade. É a esse respeito que Valla anuncia, sem temor, o ganho de causa ao partido epicurista. E por isso, podemos dizer de Valla ser um epicurista? Como chamamos a atenção anteriormente, é difícil a utilização de etiquetas quando se trata da retórica valliana. Para o humanista, professor de retórica, é na união do prazer e da utilidade que o saber se realiza. Daqui advém sua preocupação constante com a forma do texto.

Por isso, acredito que se deva ter cuidado quando lemos em Cassirer que Valla não combateu, "em nenhuma passagem, diretamente o dogma", não inovando em nada no conteúdo, mas apenas na forma (Cassirer, 200I, p.I3I). Ora, se se reconhece que Valla empregara uma nova forma como arma de combate, a resposta está nela mesma. O humanista não poderia falar tão bem no lugar de um estoico ou no lugar de um epicurista, como se propusera, não houvesse varado horas e livros discutindo seus conceitos e argumentos à maneira deles mesmos; isto é, dos escolásticos - com o mesmo espírito analítico que empregavam nas disputationes quaestionum. Esse repertório pode ser conferido na sua Dialética, por exemplo. Mas pode também ser conferido pelo seguinte exercício: despir suas obras da roupagem elegante que com tanto esforço as vestira. O que se 
encontrará ali é uma estrutura sólida e precisa; os conceitos, bem distinguidos e empregados. Como disse antes, ele faz de sua obra uma obra de arte arquitetônica cuja estrutura, pesada, rude e pouco convidativa, pode ser ocultada com os ornamentos da elegância.

Toda forma de saber, a ciência, só pode ser dita um bem enquanto nos cause algum prazer: sua utilidade última é posta no sentido dos efeitos de seus resultados, não apenas pelas conveniências úteis que produz. Se o saber é só áspero, só rude e dele não fruamos nenhum prazer, então não pode ser considerado um autêntico bem. Era o caso da disciplina Dialética (dita Lógica ou Filosofia), que se sobrelevava no ensino da Faculdade de Artes às disciplinas da Eloquência (a Gramática e a Retórica). Valla entende que a perfeita harmonia entre a Eloquência e a Dialética - ou seja, prazer e ciência (doutrina)- só é possível quando a última se submete ao governo da primeira.

Nesse sentido, podemos contextualizar a escrita posterior de suas obras, a Dialética e da Elegância da Língua Latina, ambas de I440, como tentativas do autor em firmar esses princípios: a conjunção entre prazer e doutrina. Assim, é através da poesia que ele encontra a justa libação do novo casamento. Pela boca do beato Raudense, ao final do diálogo, tece a elegia do paraíso: uma rica descrição das recompensas destinadas àqueles que confiam sua salvação em Cristo, ao mesmo tempo em que é preparado um esplendoroso banquete, regado a muito vinho, no jardim epicurista do poeta Maffeo Vegio.

\section{Referências Bibliográficas}

ADAMI, Ana Letícia. $O$ De voluptate de Lorenzo Valla: tradução e notas. Renascimento/História, Faculdade de Filosofia, Letras e Ciências Humanas da Universidade de São Paulo, Dissertação, São Paulo, 2010.

CASSIRER, Ernest. Indivíduo e cosmos na filosofia do Renascimento. São Paulo: Martins Fontes, 200I.

CHIAPPETTA, Angélica. Ad animos faciendos: comoção, fé e ficção nas Partitiones oratoriae e no De officiis de Cícero. Tese, São Paulo, 1997.

FOCAULT, Michel. O Uso dos Prazeres. In: História da Sexualidade (Volume II). Rio de Janeiro: Graal, 1977.

GARIN, Eugênio. Ciência e vida civil no Renascimento italiano. São Paulo: Unesp, 1996.

HAZLITT, Willian. “On classical education”. In: The Selected Writtings of Willian Hazlitt (Vol.

2). The round table, I8I7. London: Pickering \& Chatto, I998, p. 9. 
HORÁCIO. A Arte Poética.TRINGALI, Dante (trad.), São Paulo: Musa, I993.

HUME, David. A arte de escrever ensaios e outros ensaios. PIMENTA, Pedro Paulo e SUZUKI, Márcio (orgs.). São Paulo: Iluminuras, Coleção Biblioteca Pólen, 201 II.

KRISTELLER, Paul Oskar. Il pensiero e le arti nel renascimento. Roma: Donzelli, I998.

LEBRUN, Gérard. A neutralização do prazer. In: MOURA, Carlos Alberto Ribeiro de; CACCIOLA, Maria Lúcia M. O.; KAWANO, Marta (orgs.).A filosofia e sua história. São Paulo: Cosac Naif, 2006.

LE GOFF, Jacques; SCHMITT, Jean-Claude. Dicionário Temático do Ocidente Medieval (2 Vols.). São Paulo: EDUSC, Imprensa Oficial do Estado, 2006.

PIRES, Francisco Murari. Indagações sobre um método acima de qualquer suspeita. Revista de História e Historiografia, Outo Preto, dezembro, n.13, 2013, p.24-44.

VALLA, Lorenzo. Sur le plaisir. ONFRAY, Michel (org.), CHAUVEL, Laure (trad.). RhôneAlpes, France: La Bibliothèque Hèdoniste, Encre Marine, 2004.

VALLA, Lorenzo. De Voluptate (On Pleasure). HIEATT, A. Kent e LORCH, Maristella de Panizza (trad.). United States of America: Abaris Book, 1977.

ZANTA, Léontine. La renaissance du stoicism au XVI siècle. Paris: Librairie Ancienne Honoré Champion, Book Renaissance, I9I4. 